\title{
A violência: realidade cotidiana
}

\author{
Carlos Alberto da Cunha Almendra* e \\ LUZIa FÁTIMA BAIERL **
}

\begin{abstract}
Resumo: O presente artigo pretende tratar o fenômeno da atual proliferação da violência, procurando fornecer subsídios para sua conceituação como um fenômeno antroposociológico característico das cidades e metrópoles modernas. Analisando as diversas linhas e eixos de estudos, procura mostrar que a violência e, principalmente, o crime constituem objetos de estudos acadêmicos necessariamente prioritários para antropólogos, sociólogos, biólogos, neurologistas, assistentes sociais e toda a gama de pesquisadores voltados para a explicação e a interpretação da sociedade moderna.
\end{abstract}

Palavras-chave: violência; crime; medo social; medo coletivo e individual.

Etimologicamente, o termo violência vem do latino violentia, palavra composta de vis que quer dizer força, ou seja, é a aplicação de uma força sobre algum objeto ou fato. Hoje, significa uma "agressão física ou moral, direta ou indireta, individual ou coletiva, contra a pessoa, atingindolhe bem jurídico de que é titular, como a honra, a liberdade, a integridade física, a vida" (Valverde, 2000, p. 2).

O Dicionário Houaiss conceitua o termo como "ação ou efeito de violentar, de empregar força física (contra alguém ou algo) ou intimidação moral contra (alguém); ato violento, crueldade, força". Juridicamente, ele o define como "constrangimento físico ou moral exercido sobre alguém, para obrigá-lo a submeter-se à vontade de outrem; coação".

Nas línguas latinas, a palavra violência está estreitamente ligada ao uso da força de forma exagerada, impetuosa, excessiva, assim como de um poder - domínio - sobre outras pessoas

\footnotetext{
* Doutor em Ciências Sociais (Antropologia Urbana) e professor-adjunto do Centro de Economia e Administração da Pontifícia Universidade Católica de Campinas. E-mail: almpai@terra.com.br.

** Doutora em Serviço Social e professora da Faculdade de Serviço Social da Pontifícia Universidade Católica de São Paulo. E-mail: baierl@uol.com.br.
}

ou coisas. No alemão, temos gewalt, que tanto pode significar poder como violência, ou seja, também apresenta uma conotação de agressão e uso desmesurado e descabido de um poder, constituído em autoridade. Assim, sempre vamos encontrar a palavra violência empregada para designar o exercício de um poder ou autoridade sem legitimidade, impossibilitando a resistência, o conflito ou a recusa.

Para Aristóteles, a violência é tudo aquilo que se origina no exterior da pessoa e conflita com o próprio desenvolvimento interior da natureza humana. Evidentemente, ele se referia especificamente ao fato de alguém ser obrigado, contra a sua vontade, a fazer alguma coisa, caracterizando uma quebra da mais característica das qualidades humanas: a vontade livre.

Na definição da Organização Mundial de Saúde (OMS), a violência é considerada uma patologia social, entendida como "a imposição de um grau significativo de dor e sofrimento evitáveis". Gilberto Velho, por sua vez, procura conceituar a violência como uma manifestação e o exercício de um suposto ou efetivo poder: "Violência não se limita ao uso da força física, mas a possibilidade ou ameaça de usá-la constitui dimensão fundamental de sua natureza. Vê-se que, de início, associa-se a uma idéia de 
poder, quando se enfatiza a possibilidade de imposição de vontade, desejo ou projeto de um ator sobre outro" (Velho, 1996. p. 10).

De uma maneira geral, existe uma tendência de considerar a violência a partir de uma noção de violação de alguma norma, fato ou direito, ou seja, ela é vista como "transgressão de regras, normas e leis aceitas por uma coletividade e das quais ela depende para continuar atuando" (Chauí, 1980, p. 16), ou então, como

um ato enlouquecido que vem de baixo para cima da sociedade, quando, na verdade, seria mais pertinente encará-la como um conjunto de mecanismos visíveis e invisíveis que vem do alto para baixo da sociedade, unificando-a verticalmente e espalhando-se pelo interior das relações sociais, numa existência horizontal que vai da família à escola, dos locais de trabalho às instituições públicas, retornando ao aparelho do Estado. (Chauí, 1980, p. 16).

Outra face da violência é aquela em que há uma manifestação de fúria explícita, na qual a pessoa perde completamente seu equilíbrio emocional e comete atos de extrema violência. Muitas vezes esses atos são creditados a dificuldades econômicas ou reações contra a miséria e o sofrimento, mas, acreditamos, como Hannah Arendt (1969, 1983 e 1994), que, quando acontece, é muito mais devido a injustiças e desesperanças em relação ao futuro imediato ou mais distante.

A fúria não é de modo nenhum uma reação automática diante da miséria e do sofrimento em si mesmos; ninguém se enfurece com uma doença incurável ou um tremor de terra, ou com condições sociais que pareçam impossíveis de modificar. A fúria irrompe somente quando há boas razões para crer que tais condições poderiam ser mudadas e não o são. Só manifestamos uma reação de fúria quando nosso senso de justiça é injuriado; tal reação em absoluto não se produz por nos sentirmos pessoalmente vítimas da injustiça, como prova toda a história das revoluções, nas quais o movimento começou por iniciativa de membros das classes superiores, conduzindo à revolta dos oprimidos e miseráveis. (Arendt, 1969, p. 63).
Assim, procurando seguir sugestões de Minayo (1994a, p. 8), pretendemos, neste trabalho, abordar a violência e a criminalidade a partir da noção de violência em rede, ou seja, da violência como uma manifestação múltipla e interligada estreitamente aos seus diversos fatores, dentro de uma rede de relacionamentos, não reduzindo seu estudo apenas à questão da delinquiência e a criminalidade.

$\mathrm{Na}$ comunidade internacional de direitos humanos, a violência é compreendida como todas as violações dos direitos civis (vida, propriedade, liberdade de ir e vir, de consciência e de culto); políticos (direito a votar e a ser votado, ter participação política); sociais (habitação, saúde, educação, segurança); econômicos (emprego e salário) e culturais (direito de manter e manifestar sua própria cultura) (Serasa, 2002, p. 3).

Entretanto, reconhecemos que, independentemente de nossos esforços, uma definição de violência seria muito difícil de atingir a objetividade necessária exigida por um estudo como este, pois,

como as noções de caos, de desordem radical, de transgressão, ela com efeito envolve a idéia de uma distância em relação às normas e regras que governam as situações ditas naturais, normais ou legais, como definir o que não tem regularidade nem estabilidade, um estado inconcebível no qual tudo pode acontecer. (Michaud, 1989, p. 12)

O mesmo autor conclui:

Há violência quando, numa situação de interação, um ou vários atores agem de maneira direta ou indireta, maciça ou esparsa, causando danos a uma ou várias pessoas em graus variáveis, seja em sua integridade física, seja em sua integridade moral, em suas posses, ou em participações simbólicas e culturais (Michaud, 1989, p. 11)

Ainda dentro da perspectiva de conceituação do fenômeno representado pela violência, vamos encontrar em Engels, na sua obra AntiDühring, uma ligação da violência com o exercício do poder de uma classe social sobre a outra, consequiência de uma desigual distribuição da riqueza, que se materializa em uma sociedade 
de classes. A violência seria uma maneira de manter esse estado de coisas de forma institucionalizada e referendada pelo Estado, para garantir a propriedade, a partir da ação de um poder armado sob seu controle (Engels, 1979). Essa violência é aquela entendida como violência estrutural, considerada por Engels como típica da sociedade capitalista, conseqüência da contradição fundamental da sociedade (capital e trabalho), e define as formas de repressão social que asseguram que os conflitos sejam contidos, reprimidos e atenuados, quer pela força repressiva em si, quer por políticas sociais compensatórias. Entretanto, convém notar que essa mesma violência ocorreu durante os regimes ditos socialistas e de inspiração marxista, quando instituições do Estado trancafiaram, torturaram ou, simplesmente, eliminaram fisicamente os opositores incômodos ao regime.

Assim, as instituições estatais, particularmente aquelas que foram criadas para garantir os direitos básicos do cidadão, a sua segurança e liberdade, podem ser apropriadas por uma parcela privilegiada da população e colocadas para barrar as reivindicações dos seus setores marginalizados, no sentido de garantir seus privilégios e espaços conquistados pelo poder do dinheiro. Assim, "do ponto de vista das elites, a ênfase na necessidade de uma melhor segurança, geralmente privada, parece ser uma resposta ao que elas sentem como sendo invasão indevida da cidade e do espaço da cidadania pelas camadas populares e pelas minorias" (Caldeira, 1991, p. 173).

Essa ligação estreita com o exercício do poder caracteriza, de certa forma, as relações violentas. Hannah Arendt relacionou muito bem essas duas categorias quando afirmou: "[...] nada, como veremos, é mais comum do que a combinação de violência e poder, nada é menos freqüente do que encontrá-los em sua forma pura e, portanto, extrema" (Arendt, 1994, p. 39).

Autores como Hannah Arendt procuram distinguir poder de violência, caracterizando o exercício da violência como um meio para chegar ao poder e não um fim em si mesmo. Esse posicionamento é compartilhado por vários outros autores que, de uma forma mais mitigada ou explícita, seguem pelo mesmo caminho: "a violência como o não-reconhecimento do outro, a anulação ou a cisão do outro (Adorno, 1993 e 1995; Oliveira, 1995; Paixão, 1991; Tavares dos Santos et al., 1998; Zaluar, 1994); a violência como a negação da dignidade humana (Brant, 1989; Caldeira, 1991; Kowarick e Ant, 1981); a violência como a ausência de compaixão (Zaluar, 1994); a violência como a palavra emparedada ou o excesso de poder (Tavares dos Santos et al., 1998)" (Zaluar \& Leal, 2001, p. 3). Em todos esses posicionamentos, fica ressaltada a presença física do opositor ou a arbitrariedade dos poderosos - ou as duas - como característica da violência.

No Brasil, inclusive, tem sido Tavares dos Santos quem tem teorizado sobre esses fatores, particularmente sob a influência de Foucault e Bourdieu, definindo a violência como "excesso de poder que impede o reconhecimento do outro - pessoa, classe, gênero ou raça - mediante o uso da força ou da coerção, provocando algum tipo de dano, configurando o oposto das possibilidades da sociedade democrática contemporânea" (Tavares dos Santos et al., 1998). De acordo com essa conceituação,

desapareceria a fronteira entre a violência física, a qual oprime pelo excesso da força corporal ou armada, e a simbólica, a qual exclui e domina por meio da linguagem. Não haveria, portanto, um nicho especial para tratar da violência como o uso de instrumentos da força bruta (Zaluar, 1999), desarticulada da violência simbólica presente no institucional ou no Estado. (Zaluar \& Leal, 2001, p. 3)

De uma maneira geral, os pesquisadores da violência urbana procuram analisar o aumento da violência e da criminalidade através das "taxas de mortalidade por causas externas". As explicações aparecem ligadas à rápida concentração populacional em um organismo metropolitano que cresce sem qualquer tipo de planejamento urbano, ao desemprego, à má distribuição de renda, à pobreza, à presença do crime organizado, ao narcotráfico e à dificuldade de resposta das instituições públicas diante do aumento da criminalidade (Zaluar et al., 1994; Minayo, 1994a e 1994b; Lima \& Ximenes, 1998). Entretanto, também é consenso, nenhum desses fatores por si só pode explicar a violência em suas causas e motivações, mas fazem parte 
de uma rede de relações complexas de transformações socioeconômicas, políticas e institucionais da sociedade atual, ou seja, das chamadas "sociedades complexas" (Adorno, 1993; Zaluar et al., 1994).

O fato que se destaca, entretanto, é o aumento da criminalidade, em especial a mortalidade por homicídios, durante toda a década de 1990 - que passou de 20,9 para 27 por $100 \mathrm{mil}$ habitantes, em 2002, aumento esse notado, particularmente, entre jovens do sexo masculino com idades entre 15 e 24 anos, que passou de 35,2 para 52,1 (Suwwan, 2002a, p. C4), "deixando o país em $3^{\circ}$ lugar no ranking da Unesco (Organização das Nações Unidas para a Educação, Ciência e Cultura), atrás de Colômbia e Porto Rico" (Suwwan, 2002b, p. C4).

No caso das regiões metropolitanas, parece haver certa correlação entre o processo de espraiamento das cidades em direção à periferia, formando aglomerados urbanos precários e inseguros (Rolnik, 1999), com péssimos indicadores relativos às condições de qualidade de vida, e o aumento dos índices de homicídios

A violência urbana, entretanto, é aquela que atinge diretamente o maior número de pessoas, já que a população se concentra e tende a se concentrar cada vez mais nas cidades. Ela não engloba apenas os crimes, mas tudo o que está relacionado a eles, já que interfere no cotidiano das pessoas e organizações, corroendo a qualidade de vida das pessoas.

Gangues urbanas, pichações, depredação do espaço público, o trânsito caótico, as praças malcuidadas, sujeira em período eleitoral compõem o quadro da perda da qualidade de vida. Certamente, o tráfico de drogas, talvez a ramificação mais visível do crime organizado, acentua esse quadro, sobretudo nas grandes $\mathrm{e}$ problemáticas periferias. (Serasa, 2002, p. 5)

As dificuldades para definir, com clareza, os objetos de estudos violência e criminalidade são evidentes se considerarmos a grande quantidade de trabalhos que procurou tratar o tema.

Entretanto, entre eles, temos os trabalhos de Minayo \& Souza (1997-1998), que conseguiram produzir um suporte bastante eficiente para balizar os estudos sobre violência, apesar de abordarem o tema sob a perspectiva da saúde. Assim, nesses trabalhos, a pesquisadora procura englobar em dois grandes agrupamentos as teorias que tentam explicar o fenômeno violência em toda a sua abrangência:

De um lado estão os que sustentam que a violência resulta de necessidades biológicas, psicológicas ou sociais, fundamentando-se na sociobiologia ou na etologia, teorias que subordinam a questão social às determinações da natureza. De outro, estão os que explicam a violência como fenômeno de causalidade apenas social, provocada quer pela dissolução da ordem, quer pela 'vingança' dos oprimidos, quer ainda pela fraqueza do Estado. (Minayo \& Souza, 1997-1998, p. 3)

A partir daí, através de desdobramentos, vários outros grupos se formaram, dentre os quais destacamos quatro principais:

$O$ primeiro grupo considera a sociedade um teatro onde se desenrola uma competição entre indivíduos, grupos e nações, seguindo abordagens a partir das idéias de Hobbes, segundo as quais as pesquisas podem produzir padrões científicos de comportamento, aplicáveis para explicar fenômenos de natureza violenta. Para eles, é possível encontrar uma explicação neutra, rigorosa e isenta de influências da moralidade, apenas controlando os juízos de valor utilizados na descrição do fenômeno violência (Minayo \& Souza, 1997-1998, p. 3). Essas teorias partem da própria naturalização da violência, considerando a agressividade humana como uma característica inata e, portanto, os atos de violência são eternos e naturais, expressos de forma mais ou menos evidente, de acordo com a época histórica vivida. Várias outras teorias, seguindo as mesmas premissas anteriores, substituem o processo histórico e social pelo conceito de agressão proveniente da biologia, etologia, genética e medicina (Minayo \& Souza, 1997-1998, p. 4), que consideram essa agressividade como parte do próprio instinto de sobrevivência. Assim, de certa forma, subordinam o social ao biológico, como enfatiza William Thorpe (1970, p. 40), quando declara: "dificilmente existe algum aspecto da conduta dos animais que não tenha referência nos problemas da conduta humana". 
As descobertas da etologia social, particularmente a partir dos trabalhos de Lorenz (1979, p. 25), permitiram perceber que o mecanismo da agressividade instintiva manifesta-se automaticamente em determinadas circunstâncias (perigo, sobrevivência e reprodução, principalmente), levando os animais a atacarem outros da mesma espécie. A agressividade, assim, é considerada pelo autor citado e seus seguidores como necessária à própria preservação da espécie, de forma natural e irresistível, reduzindo os condicionantes socioantropológicos aos biopsicológicos.

Edward Morin (1970, p. 46-9) considera que a violência que se expressa no cotidiano de nossa sociedade é consequiência da estimulação de atavismos arcaicos e da "exacerbação de soluções neuróticas a curto ou longo prazos" (Minayo \& Souza, 1997-1998, p. 5). Sob essa ótica, o problema da violência não é de índole social, mas psicológica, o que possibilita dizer que qualquer transformação nas relações sociais só será possível a partir de uma modificação psicológica - e não social - na índole do ser humano.

Mesmo considerando que os estudos da biologia, da psicologia, da genética e da neurofisiologia são extremamente importantes para o entendimento do humano que caracteriza o homem, não podemos deixar de enxergar a violência como uma construção social, da vida em sociedade, estimulada pelas peculiaridades individuais de cada um, ou seja, pela sua própria história de vida, cujo comportamento em sociedade é nada mais, nada menos que a concretização visível e exteriorizada dessa história individual em suas múltiplas relações. Para tanto, temos que concordar fortemente com Minayo $\&$ Souza, quando cita Marx e Engels, atribuindo a violência a um comportamento humano estimulado fortemente pelo poder da sociedade:

Aqui se argumenta em favor da relação dialética entre indivíduo e sociedade, e não da prioridade do primeiro sobre a segunda. Marx e Engels (1971, p. 146) exprimiram bem esse ponto de vista ao afirmarem que: "O homem desenvolverá sua verdadeira natureza no seio da sociedade e somente ali; razão pela qual devemos medir o poder de sua natureza não pelo poder do indivíduo concreto, mas pelo poder da sociedade". (Minayo \& Souza, 19971998, p. 5)

O segundo grupo trata a violência a partir da premissa de que ela é socialmente causada, produto direto das desigualdades sociais, nas quais as condições de extrema pobreza convivem com extrema riqueza e desperdício, provocando a desesperança e a criminalidade. Estes são frutos diretos da urbanização acelerada e sem qualquer tipo de planejamento, causada pelo processo de industrialização dependente e predatório. Como afirmam Merton (1968) e Huntington (1968), esses fenômenos provocam correntes migratórias importantes para as periferias das grandes metrópoles, em condições de grande pobreza, desenvolvendo novos tipos de comportamentos e novas moralidades, o que faz com que essas pessoas sejam presas fáceis do crime organizado e do tráfico de drogas. Assim, as grandes cidades seriam os centros geradores de delinqüiência e de criminalidade.

$O$ terceiro grupo, ainda de acordo com Minayo (1997-1998, p. 5), seria formado por populações que, como estratégia de sobrevivência diante de tal desigualdade social, apelam para a violência.

Tais idéias inspiram-se basicamente em Sorel (1970), o primeiro teórico da explicação da violência como revolta dos despossuídos, e em Engels (1974), que situa o fenômeno da delinqüência no início da industrialização da Inglaterra como nível elementar da luta de classes. Pires (1986), Oliven (1983, 1992) e Cerqueira (1987) são, entre nós, alguns dos representantes dessa corrente. Ela retém uma visão exterior da violência, como força instrumental de reposição da justiça, e deixa de lado outros aspectos da violência social e cultural que têm raízes estruturais profundas e internalizadas nos sujeitos, e que atingem a todos nós, independentemente de classe, cor, raça, sexo ou idade. (Minayo \& Souza, 1997-1998, p. 7)

Entretanto, foi Hegel (1969, p. 299-336) quem primeiro considerou a violência como ligada à própria origem da consciência humana. A partir daí, Freud (1974, p. 311) e Habermas (1980, p. 100) desenvolvem mais essa teoria, considerando que o próprio processo civilizatório 
oferece meios para controlar essa violência como manifestação humana.

Um quarto grupo explica a violência crescente como uma falha do próprio organismo estatal, que não consegue controlar esse processo. Preconiza como solução um Estado opressivo, autoritário e controlador, aparelhado de organizações repressivas e punitivas de efeito exemplar, para que não haja reincidência.

Hoje, a violência e o medo provocado por ela são fenômenos tão disseminados que poderíamos, tranqüilamente, falar em uma epidemia de violência, que constitui um problema de saúde pública.

Se o fenômeno da violência, como diz Engels (1972, p. 27), é produto da história - esta "é como a mais cruel das deusas que arrasta sua carroça triunfal sobre montões de cadáveres" -, não se pode deixar de reconhecer que os processos violentos inibem, modificam e enfraquecem tanto a qualidade como a capacidade de vida. Vários estudiosos da atualidade observam que se torna cada vez mais necessária uma epidemiologia da violência, inclusive uma epidemiologia dos problemas psiquiátricos gerados por ela. (Minayo \& Souza, 1997-1998, p. 9)

A violência também é entendida como uma rejeição do outro, representado pelo favelado ou pelo pobre que pede dinheiro ou vende quinquilharias, em uma sociedade de exclusão e xenofobia, a partir da constatação que esses indivíduos são considerados diferentes, estranhos e estrangeiros, como muito bem lembrou Balandier (1997, p. 212). O medo do diferente, daquele que não se encaixa nos padrões da normalidade econômica e cultural, tem como conseqüência principal o aumento da própria violência contra essas pessoas. Por isso, a sociedade, particularmente as mais tradicionais, tem a presença constante da violência e o clamor social de controlá-la a qualquer custo, dentro de padrões e situações que não ameacem a ordem constituída e as pessoas economicamente mais significativas. É necessário domesticar a violência, confiná-la nos recônditos do particular e da vida doméstica, ritualizá-la de forma a prevenirse contra sua ação de subversão ou perturbação (Balandier, 1997, p. 208). Esses elementos, causadores da desordem, ${ }^{1}$ ou seja, peças que não funcionam harmoniosamente em relação ao todo social, precisam ser reprimidas, controladas e imobilizadas, razão pela qual o clamor por uma polícia presente e vigilante, agindo contra qualquer tipo de anomalia social, aparente ou real.

Assim, levando em consideração as observações anteriores, admitiremos que a violência seja um fenômeno histórico-social, datado no tempo e no espaço, no qual se diferencia e categoriza (Burke, 1995; Pinheiro, 1982; Farjado, 1988). Revela uma fragilidade e estrutura de classe, etnia, faixa etária, gênero etc. "A desvalorização da vida e das normas convencionais, das instituições, dos valores morais e religiosos, o culto à força e ao machismo, a busca do prazer e do consumo imediato estão hoje na base dos códigos paralelos das gangues e 'falanges' que amedrontam nossos centros urbanos" (Minayo \& Souza, 1997-1998, p. 8). Esses fatos, para serem minimamente entendidos, provocam a necessidade de se estabelecer redes entre os seus diversos fenômenos e protagonistas, como propõem Da Matta (1982), Domenach (1981) e Boulding (1981). Além disso, aspectos culturais são fundamentais para explicar determinados tipos de comportamento social que, eventualmente, podem se considerados violentos (Burke, 1995; Cruz Neto \& Minayo, 1995; Oliven, 1993 e Chesnais, 1981).

1. "Para Balandier (1997, p. 11), a desordem é um conceito importante para se compreender a sociedade moderna, na qual predominam o movimento e a incerteza. O movimento se realiza em múltiplas formas, vistas por muitos como armadilhas ou como máscaras da desordem. Considerando que ordem e desordem são duas faces da mesma moeda e que se referem sempre à relação do todo e das partes nos conjuntos de elementos e nas sociedades, o autor assim as define: 'Existe 'ordem' quando os elementos não existem sem ligação, mas têm entre si um princípio de unidade que os faz participar, ao mesmo tempo, de um conjunto único [...]. Existe desordem quando os elementos de um conjunto, fazendo parte desse todo, comportam-se como se não fizessem parte' (p. 47). A desordem é, geralmente, vista sob o aspecto do mal ou do inesperado, do incomum. Por isso, todas as sociedades reservam um lugar para ela, mesmo temendo-a; por não terem a capacidade de eliminá-la, precisam encontrar formas de compor-se com ela (p. 121). No entanto, a modernidade parece atribuir-lhe uma capacidade de onipresença e de crescente virulência, transformando-a na principal referência obsedante e fixadora de incompreensões, inquietudes e angústias (p. 194)" (Teixeira \& Porto, 1998, p. 66). 
Por essas razões, podemos afirmar que vivemos uma sociedade do espetáculo, onde cada um tem que ter os seus quinze minutos de exposição e glória e da cultura narcísica do indivíduo, em que a auto-admiração e o culto à personalidade prevalecem sobre qualquer outro impulso individual. Para atingir esses objetivos, tudo é particularmente válido, mesmo a violência e o crime. Assim, percebemos certa facilidade e prazer em bandidos contando seus casos em entrevistas. É o prazer da exposição da personalidade.

Os psicopatas, exemplos de pessoas violentas e sem consciência moral, são "o que de mais temível e intrigante os descaminhos da mente humana podem produzir. Eles são eloqüentes, charmosos, sedutores e capazes de impressionar e de cativar rapidamente. Parece bom? Somem-se a essas características insensibilidade, frieza, mentiras, uma brutal capacidade de manipulação e nenhum sentimento de culpa ao fazer o mal" (França, 2002, p. 36). São classificados pela Organização Mundial de Saúde como portadores de um distúrbio patológico de comportamento anti-social, que incide em 5\% da população mundial.

Quanto à origem da violência, existe controvérsia nos meios científicos. Biólogos e neurologistas procuram encontrar na anatomia e na fisiologia humanas pistas para definir tendências genéticas de violência nos indivíduos. Sociólogos e antropólogos, assim como os demais cientistas sociais, procuram definir condições sociais, culturais e educacionais para o desencadeamento dos atos violentos.

Segundo Flores (2002), a relação entre genética e criminalidade violenta e sistemática aparece como um transtorno da personalidade que se manifesta de forma crônica na segunda década de vida do agente violento, caracterizada pela ausência de culpa, vergonha ou remorso, pobreza de relações afetivas, incapacidade de aprender com a experiência e insensibilidade social. Ainda identifica certas condições que agravam ainda mais o problema, quais sejam: fragilidades biológicas causadas por problemas neurológicos, atraso no desenvolvimento neuropsicomotor e complicações de parto, combinadas com um ambiente familiar inadequado, especialmente no primeiro ano de vida.
Alguns estudos recentes, particularmente de pesquisadores ligados à Universidade Estadual de Campinas (Unicamp), estão se referindo a uma semente de violência que todos os seres humanos possuem. Somos todos violentos, uns mais, outros menos, segundo o biomédico da Unicamp Renato Sabbatini (Barata \& Scholer, 2001, p. 1). Ele afirma que o homem é a espécie mais violenta do planeta e que seu cérebro está relacionado com isso.

Também na Pontifícia Universidade Católica de Campinas (PUC-Campinas) encontramos estudos que apontam nessa direção, como o seguinte:

Geraldo José Ballone, médico psiquiatra da Pontifícia Universidade Católica de Campinas, chama a atenção para a importância do comportamento violento em nossa espécie: "a agressividade, matriz psicofisiológica da agressão, faz parte de nosso arsenal de comportamentos dirigidos à adaptação. $\mathrm{O}$ ser humano não sobreviveria sem a agressividade". (Barata \& Scholer, 2001, p. 1)

As explicações que fundamentam esse ponto de vista estão baseadas no comportamento competitivo que o homem tem desde as mais remotas eras, quando tinha de lutar violentamente pela sua sobrevivência e pela propagação do seu estoque genético.

Em alguns momentos, esses pesquisadores quase resgatam as teorias lombrosianas de criminalidade: "muitos estudos têm mostrado que assassinos criminosos ultraviolentos têm anormalidades no globo frontal', mas salienta que 'existe razoável evidência que os sociopatas têm uma disfunção no cérebro frontal. Por que e quando esta disfunção aparece ainda é totalmente desconhecido"' (Barata \& Scholer, 2001, p. 2).

Para Ferraz (1994), o estudo da violência inerente ao homem deve ser realizado observando a natureza própria do homem e o seu ambiente. No primeiro caso, teremos de averiguar a natureza instintiva do homem para a violência; no segundo, a influência causada pelo meio em que está inserido: a cidade, desconsiderando o fato de que o homem só se torna violento pela influência externa, ou seja, a 
violência é um estado imposto pelo ambiente social, e não inato.

Se considerarmos, como Ferraz (1994), o homem como sendo uma espécie violenta, que executa assassinatos em massa, e a grande maioria da população com características de desajustamentos comportamentais, visão corroborada por Fromm (1979) - que o classifica como portador de uma violência letal -, temos de concluir ser o homem dotado de um grande impulso para a destruição e a crueldade, "sendo este, em contraste com a maioria dos mamíferos, um autêntico assassino" (Fromm, 1979).

Em experiências com animais, nas quais foram estudados os efeitos da superpopulação no comportamento de seus membros, provocando uma grande densidade demográfica, percebeu-se um aumento rápido da agressividade e da violência entre eles à medida que aumentava a relação população/espaço (Hall, 1989). Essa diminuição do espaço individual de cada um provoca uma afetação no seu sentido de territorialidade, isto é, espaço individual disponível. Assim, a grande pergunta é: isso ocorre também na espécie humana? Em que nível a educação e a cultura de cada um vão sublimar esses instintos, substituindo-os por reações racionais? "Enfim, a coabitação sem possibilidade de expansão real resulta na selvageria individual (para evitar o controle social) e, consequientemente, na agressividade" (Castells, 1969, p. 103). "A diversificação das atividades e dos meios urbanos provoca uma forte desorganização da personalidade, o que explica a progressão do crime, do suicídio, da corrupção, da loucura, nas grandes metrópoles" (Castells, 1969, p. 104). Particularmente, preferimos investir na crença de que a cultura e a educação podem humanizar o homem o suficiente para ele poder controlar os seus possíveis instintos agressivos, e desenvolver um comportamento socialmente mais adequado para a sua sobrevivência e de sua espécie. Balandier (1997, p. 208) afirma que, nas sociedades tradicionais, a violência está sempre presente, controlada por regras que coíbem ou sancionam (pena de morte) o homicídio, as guerras (aceitáveis contra o estrangeiro, inimigo real ou potencial), a violência formadora (educação e socialização das crianças e adolescentes), permanecendo domesticada, ritualizada. Nas sociedades modernas, segundo o mesmo autor (p. 211), a violência aparece ampliada tanto na sua visibilidade como na consciência de sua existência, pois o Estado não consegue reprimir suas manifestações, como atestam os aumentos gradativos da criminalidade e da insegurança urbanas. Ocorre, então, certa naturalização da violência, o que Geertz (1989) chamou de cultura da violência, entendida a cultura como uma prática social de significados, tecida pelo homem e na qual ele se enreda.

De uma maneira geral, podemos

afirmar que a violência é construída socialmente, tanto do ponto de vista do ato propriamente dito, quanto do significado a ele atribuído. É necessário que a sociedade em que ele ocorre o considere violento. A violência existe a partir do momento em que está institucionalizada; quando a sociedade produz um discurso que justifica aquele ato como fora da norma e, para isto, é necessário que haja um processo de cristalização do universo simbólico que envolve esse ato, o que pode ser captado através da análise destes discursos. (Barroso, 1997, p. 40-41)

A grande polêmica entre os estudiosos das manifestações de violência continua sendo, na verdade, sobre o quanto a pobreza influi na explosão dos atos violentos. "Os principais argumentos críticos à associação entre crime e pobreza foram levantados principalmente por Campos $(1978,1980)$ e desenvolvidos, seguindo outras metodologias, por Paixão (1983), Zaluar (1985, 1989), Campos Coelho (1987), Bordini (1989) e Abreu (1980), entre outros" (Misse, 1993 , p. 6). Essa associação, também a nosso ver, é inadequada, pois "Tanto como estereótipo, ou como correlação estatística, quanto como 'adequação causal de sentido' ela é efetivamente espúria e socialmente perversa" (1993, p. 6).

Convém notar que, dentro dessa perspectiva, a Prefeitura de São Paulo elaborou uma pesquisa, Pobreza e violência no município de São Paulo, feita pela Secretaria de Desenvolvimento, Trabalho e Solidariedade (Silva, 2002a, p. C3), que comparou dados de 1991 e 2000. A constatação foi a seguinte: pobreza e violência estão sempre juntas, mesmo que não 
sejam causa ou conseqüência uma da outra, ou seja, "quanto maior a taxa de crescimento anual do número de chefes de família pobres de um distrito, maior a chance de essa região ter de conviver com aumento das mortes violentas. Situação oposta ocorre em áreas onde houve arrefecimento da pobreza. Nelas predominam também decréscimo das taxas de mortes violentas" (Silva, 2002a, p. C3). E, para tornar o fato mais claro, pesquisando as áreas com aumento de pobreza, constatou-se que houve nelas um aumento proporcional de violência: "O resultado mostrou que, dos dez distritos com maior média anual de taxa de crescimento de chefes de família pobres, em oito a taxa média de aumento do número de homicídios e de mortes no trânsito também cresceu" (Silva, 2002a, p. C3).

A pobreza, entretanto, não é causa suficiente para alavancar a violência, mas viver na pobreza é estar mais exposto a ter baixa escolaridade, baixa expectativa de melhores condições de vida e, principalmente, consciência de menores possibilidades de acesso a melhores condições de vida, o que, agindo conjuntamente, pode levar algumas pessoas à desesperança e à prática de atos violentos

Por outro lado, a pesquisa também mostrou que "pobreza e violência estão diretamente associadas ao nível de industrialização de um distrito" (Silva, 2002b, p. C4). Além disso, esses dados são congruentes com os níveis de escolaridade exigidos pela atividade industrial: quanto mais sofisticada for a indústria, maior o nível de escolaridade exigido e menores as taxas de violência, comprovando a ação conjunta de todos esses fatores e não, apenas, a pobreza.

Um dos principais argumentos usados para entender a motivação da violência e da criminalidade considera o desejo de consumo ou de status social como o grande deflagrador do ato violento, que se exterioriza quando as pessoas competem entre si, tendo como conseqüência o enriquecimento de alguns e a pauperização de muitos. Consiste em uma modalidade de violência que "nasce no próprio sistema social, criando as desigualdades e suas conseqüências, como a fome, o desemprego, e todos os problemas sociais com que convive a classe trabalhadora" (Minayo, 1990, p. 290). Além disso, trata-se, portanto, de uma violência legitimada que, do ponto de vista das classes, expressase nas desigualdades e exclusão, que gera fome, desemprego, abandono de crianças, bem como os demais problemas sociais em que as vítimas são tratadas como responsáveis. [...] Este tipo de violência presente nas instituições estabelece os limites culturalmente aceitos da violência aberta, principalmente a física, numa sociedade. (Souza, 1991, p. 17)

Foi a partir dessas constatações que Minayo \& Assis afirmaram que "a violência estrutural é a violência primordial, geradora e mantenedora de uma rede de violências" (Minayo \& Assis, 1993, p. 59), de certa forma concordando com as observações de Engels em Anti-Dühring, no qual o autor atribui às desigualdades sociais, corroboradas pelas estruturas do Estado, as causas da violência (Engels, 1979).

Uma das principais conseqüências da violência é a notabilidade do comportamento criminoso, isto é, a visibilidade social que assumem a violência e seu agente. Assim, diante da exposição pública do ato violento e criminoso, as autoridades são compelidas a dar as satisfações mais variadas de sua ineficiência. Prática essa que não é nova, pois vem de tempos mais remotos quando o comportamento criminoso foi visto a partir da ótica dos conceitos médicopsiquiátricos e higienistas europeus (Misse, 1998, p. 1). Esses conceitos foram reforçados pelos positivistas radicais republicanos, que preferiram combater o crime na cidade do Rio de Janeiro mandando para Fernando de Noronha os capoeiristas, considerados criminosos na época. Essa tendência dominou toda a primeira metade do século $\mathrm{XX}$, quando as acusações mais comuns de vadiagem e desordem deram lugar a uma "classificação menos ambígua e mais criminal e os crimes passionais (principalmente de honra ou vingança) continuavam a constituir a maioria dos casos de lesões corporais e de homicídios intencionais" (Misse, 1998, p. 3).

A polícia, de uma maneira geral, apresenta altíssimo potencial gerador de violência, tornando-se um fator de medo e apreensão por parte da população em geral. Agravando ainda mais esse fato, os inúmeros casos de corrupção existentes nos meios policiais acabam tornando 
a corporação um problema para o Estado e não uma solução para a violência e a criminalidade.

Caso fôssemos fazer, mesmo que a título de simples suposição, um cálculo da quantidade de policiais verdadeiramente corruptos no país, chegaríamos à impressionante soma de $25 \mathrm{mil}$, ou seja, não teríamos cadeias suficientes para todos, mesmo que quase todos os atuais prisioneiros fossem soltos. "Há cerca de $500 \mathrm{mil}$ policiais no país. Suponha-se que apenas 5\% deles cometam atos de delinquiência: uma minoria, sem dúvida. Mas, em números absolutos, seriam 25 mil os criminosos na PM - número suficiente para ocupar os jornais todo dia e sugerir ao articulista duras generalizações sobre a corporação" (Coelho, 2005, p. E6).

A freqüente cumplicidade policial com os traficantes presos, prática que começa a se tornar visível no mundo todo, acaba por criar uma desesperança no sentido de resolver ou, pelo menos, minorar o problema da corrupção policial.

"Você pode ter os melhores equipamentos do mundo e, se as pessoas que cuidam são corruptas, os presos vão sair pela porta da frente", afirma Geraldo Reyes, repórter para a América Latina de El Nuevo Herald e membro da equipe do jornal Miami Herald que ganhou o prêmio Pulitzer em 99. (Folha de S. Paulo, $3 /$ 12/2002, C6)

Seguindo essas normas o Centro de Readaptação Prisional (CRP) de Presidente Bernardes não permite a "nenhum agente ficar sozinho com o preso ou entrar nos pavilhões das celas sem passar antes pelo detector de metais. Tudo é acompanhado de perto e gravado, pelo sistema de câmeras. Funcionários e presos não sabem quando vão se encontrar. Há rodízio periódico de tarefas, coordenado pela direção do lugar" (Silva, 2002, p. C6). Situado a 589 km de São Paulo, é o único do país que possui bloqueadores de celulares para impedir a comunicação entre os chefes presos e os seus capangas em liberdade.

Indubitavelmente, a grande incentivadora da criminalidade e da violência é a impunidade. A impunidade atinge a imensa maioria dos criminosos, fazendo com que o crime tenha uma relação de custo-benefício imensamente favo- rável. Assim, nos últimos cinco anos, dos mais de 600 mil crimes registrados em 16 delegacias de polícia na cidade de São Paulo, apenas uma pequena parcela redundou em pena de reclusão do acusado.

Isso porque, de um total de 338,6 mil crimes, violentos e não violentos, analisados no período, apenas 21,8 mil foram objeto de inquérito policial. Estima-se com base em outros estudos que, desses inquéritos, $40 \%$ venham a ser arquivados. Se essas estatísticas se confirmarem, apenas 13,1 mil crimes se traduzirão em denúncia encaminhada ao Ministério Público e acolhida pela autoridade judiciária. "Alguns serão desqualificados por falta de provas, por exemplo, e possivelmente algo em torno de 5\% dos crimes analisados redundarão em pena", diz Sérgio Adorno, coordenador do Centro de Estudos da Violência, um dos dez Centros de Pesquisa, Inovação e Difusão (Cepids) financiados pela Fapesp. "Na França, em 20 crimes violentos, 19 tendem a merecer pena", compara [...] "Outro levantamento, sobre o assassinato de crianças e adolescentes, realizado em São Paulo entre 1991 e 1994 e já concluído, revelou taxa de conversão do crime em pena de apenas 1,72\%". (Izique, 2004, p. 2)

Essa impunidade acaba trazendo para os bandidos, particularmente nas favelas cariocas, uma aura de herói imortal e acima de qualquer punição por seus atos que, conseqüentemente, passam a ser considerados como justos e corretos. Isso estimula a imaginação das crianças, que começam a se interessar pelo tráfico e, particularmente, a desejar fazer parte dessa vida aventurosa.

Outro aspecto dessa questão extremamente importante e ignorado por parte dos estudiosos, e que se refere às pessoas que sofreram violência ou que tiveram algum contato direto com ela, é o que acontece depois com elas. Elas também devem ser consideradas vítimas ocultas da violência, como apregoa Glauco Soares, na pesquisa Vítimas ocultas da violência no município do Rio de Janeiro, realizada entre 2003 e 2004. Segundo ele, "A violência produz vítimas ocultas dos levantamentos estatísticos da criminalidade. Elas têm seqüelas físicas e psíquicas em razão da morte de 
familiares ou amigos, apesar de não terem envolvimento direto com o crime que nela resultou. São vítimas indiretas da violência que atingiu alguém por quem tinham afeto" (Monken, 2004, p. C4). Mesmo depois de muito tempo passado após o evento, "as pessoas que fizeram reconhecimento do corpo de um familiar ou amigo morto violentamente têm o dobro de chances do que aqueles que não viram de ter reações físicas pesadas - como diarréias, enjôo, vômitos, dores de cabeça, entre outras - quando lembram da morte, mesmo que tenha ocorrido há vários anos" (Monken, 2004, p. C4).

Percebemos, às vezes indignados, mas sempre impassíveis, a escalada dessa violência, particularmente deflagrada pelo narcotráfico, em que balas perdidas e guerras entre gangues produzem inúmeras vítimas inocentes. Não vemos, quer por parte dos políticos, quer por parte das instituições - mesmo as estatais -, quase nada no sentido de impedir ou coibir de forma consistente a violência do crime organizado, do crime do colarinho branco ou daqueles gerados pelas nossas estruturas sociais injustas, que limitam a cidadania e o direito à dignidade mínima (Almendra, 2007). Provavelmente isso ocorre porque o crime e a violência já tomaram conta da nossa sociedade como elemento corriqueiro (Almendra \& Baierl, 2002), tolerado por quase todos, que se sentem impotentes para ter qualquer ânimo que reverta essa situação (Baierl, 2003 e 2004). As manifestações que ocorrem por parte da sociedade civil se expressam muitas vezes como resultantes de grupos e segmentos de classe que começam a se sentir atacados diretamente pela violência, buscando geralmente soluções em torno de ações do ponto de vista da segurança pública e de ações penais mais duras. As escassas manifestações que se voltam para uma análise das causas estruturais da violência e do entendimento dela, como um fenômeno multifacetado e transversal na sociedade capitalista, ganham pouca visibilidade. Poderíamos terminar este texto com uma indagação: a quem interessa de fato o enfrentamento e a superação da violência?
Abstract: The present article intends to deal with the phenomenon of the actual violence proliferation trying to establish assistance for its conception as an anthropsociologic phenomenon characteristic of the modern cities and metropolis. Analyzing several lines and "axis" of studies, it tries to show that the violence, mainly the crime, consists of academic studies, necessarily priorities for the anthropologists, sociologists, biologists, neurologists, social assistants and all kinds of science for the explanation and interpretation of the modern society.

Key-words: violence; crime; social fear; collective and individual fear.

\section{Referências}

ADORNO, Sérgio. A criminalidade urbana violenta no Brasil: um recorte temático. Rio de Janeiro, Boletim informativo e bibliográfico de ciências sociais, $\mathrm{n}$. 35, $1^{\circ}$ sem. p. 3-24, 1993.

ALMENDRA, Carlos Alberto da C. Violência e tráfico: O indizível e o impronunciável. São Paulo, 2007. Tese (Doutorado) - Faculdade de Ciências Sociais da PUC-SP.

ALMENDRA, Carlos Alberto da C. \& BAIERL, Luzia Fátima. A dinâmica perversa da violência e do medo social. Revista serviço social e sociedade, São Paulo, n. 72, 2002.

ARENDT, Hannah. Crises of the republic, New York: Harcourt Brace Jovanovich, 1969.

. A condição humana. Rio de Janeiro: ForenseUniversitária, 1983.

. Sobre a violência. Rio de Janeiro: RelumeDumará, 1994.

BAIERL, Luzia Fátima. Personagens e enredos de cenas de medo e violência na cidade de Santo André (SP). São Paulo, 2003. Tese (Doutorado) - Faculdade de Serviço Social, PUC-São Paulo.

. Medo social - Da violência visível ao invisível da violência. São Paulo: Cortez, 2004.

BALANDIER, Georges. A desordem: elogio do movimento. Rio de Janeiro: Bertrand Brasil, 1997.

BARATA, Germana; SCHOLER, Juliana. Violência extrema pode ter causas biológicas, Comciência, $\mathrm{n}$. 26, novembro de 2001. Disponível em: http:// www.comciencia.br/reportagens/framereport.htm. Acesso em: 23 de maio de 2005.

BARROSO, Sirlene Botosi. Estudo sobre violência em um bairro periférico do município de Campinas - SP: da objetividade das "causas externas" à subjetividade de moradores e profissionais. São Paulo, 1997. Dissertação (Mestrado) - Pontifícia Universidade Católica de São Paulo. 
BOULDING, E. Las mujeres y la violência social. In: JOXE, A. (Org.). La violência y sus causas. Paris: Unesco, 1981.p. 265-79.

BURKE, P. Violência social e civilização. Braudel papers, $\mathrm{n}^{\circ} 12$, p. 1-8, 1995.

CALDEIRA, Teresa Pires do Rio. Direitos humanos ou "privilégios de bandidos"? Novos estudos, Cebrap, n. 30, julho de 1991.

CASTELLS, M. Théorie et idéologie em sociologie urbaine. Sociologie et Societés, t. 1, n. 2, 1969.

CHAUÍ, Marilena. A violência do brasileiro: um mito interessantíssimo. Almanaque $n^{o} 11$ (Educação ou desconversa?). São Paulo: Ed. Brasiliense, 1980. p. 16-24.

CHESNAIS, J. C. Histoire de la violence. 2. ed. Paris: Pluriel, 1981.

COELHO, Marcelo. Ovos, bonecas, relicários. Folha de S. Paulo. Caderno Ilustrada, p. E6, 20 de abril de 2005.

CRUZ NETO, O.; Minayo M. C. de S. Corpos e sonhos destruídos. Introdução. Rio de Janeiro: ENSP/ Fiocruz, 1995. (Mimeo).

DA MATTA, R. As raízes da violência no Brasil. In: PINHEIRO, P. S. (Org.). Violência brasileira. São Paulo: Brasiliense, 1982. p. 49-54.

DOMENECH, J. M. La violência. In: JOXE, A. (Org.). La violencia y sus causas. Paris: Unesco, 1981. p. 33-46.

ENGELS, Friedrich. Théorie de la violence. Paris: Edition 10/18, 1979.

Friedrich. Anti-Dühring: filosofia, economia política, socialismo. Rio de Janeiro: Paz e Terra, 1979.

FAJARDO, E. Em julgamento a violência no campo. Rio de Janeiro: Fase/Vozes, 1988.

FERRAZ, H. A violência urbana. São Paulo: Ed. João Scortech, 1994.

FLORES, Renato Zamora. Biologia e violência. Ciência Saúde Coletiva, 2002, vol.7, n.1, p.197-202.

FOLHADE S. PAULO. Queima de arquivo evidencia poder do PCC. Caderno Brasil, p. A3, 3/fevereiro/ 2002.

FRANÇA, Ronaldo. A fronteira da maldade. Veja, ed. $1.738,13 / 2 / 2002$.

FREUD, S. Reflexões para os tempos de guerra e morte. In: Obras completas de Sigmund Freud. Rio de Janeiro: Imago, 1974. p. 311-39.

FROMM, E. Anatomia da destrutividade humana. Rio de Janeiro: Ed. Zahar, 1979.

GEERTZ, Clifford. A interpretação das culturas. Rio de Janeiro: Zahar, 1989.
GIRARD, René. A violência e o sagrado. São Paulo: Unesp/Paz e Terra, 1990.

HABERMAS, Jurgen. O conceito de poder em Hannah Arendt. In: Habermas. São Paulo: Ática, 1980.

HALL, EDWARD T. A dimensão oculta. Rio de Janeiro: Francisco Alves, 1989.

HEGEL, G. F. Filosofia dei espíritu. Buenos Aires: Ed. Claridad, 1969.

HUTINGTON, S. Political order in changing societies. Nova York: New Heaven, 1968.

IZIQUE, Claudia. Impunidade e violência. Revista Pesquisa, ed. 96, fevereiro de 2004.

LIMA, M. L. C.; XIMENES, R. Violência e morte: diferenciais da mortalidade por causas externas no espaço urbano do Recife. Cadernos de Saúde Pública, n. 14(4), out/dez, 1998, p.829-840.

LORENZ, K. A agressão, uma história natural do mal. 2. ed. Lisboa: Ed. Moraes, 1979.

MARCONDES FILHO, Ciro. Violência fundadora e violência reativa na cultura brasileira. São Paulo Perspectiva, vol. 15, n. 2, p. 20-27.

MERTON, R. Sociologia, teoria e estrutura. São Paulo: Mestre Jou, 1968.

MICHAUD, Yves. A violência. São Paulo: Ática, 1989.

MINAYO, Maria Cecília de Souza. A violência na adolescência: Um problema de saúde pública. Caderno de Saúde Pública, 6 (3), jul-set/1990.

MINAYO, Maria Cecília de Souza. O desafio do conhecimento: pesquisa qualitativa em saúde. 3. ed. São Paulo/Rio de Janeiro: Hucitec-Abrasco, 1994a.

. A violência social sob a perspectiva da saúde pública. Cadernos de Saúde Pública, vol.10, n. 1, suplemento, 1994b.

MINAYO, Maria Cecília de Souza; ASSIS, S. G. Violência e saúde na infância e adolescência: uma agenda de investigação estratégica. Saúde em debate, n. 39, p. 85-93, 1993.

MINAYO, M. C. de S.; SOUZA, E. R. de. Violência e saúde como um campo interdisciplinar e de ação coletiva. História, Ciências, Saúde, vol. IV, n.3, p. 513-531, nov. 1997-fev. 1998.

MISSE, Michel. Crime e pobreza: velhos enfoques, novos problemas. In: GONÇALVES, M.A.; VILLASBOAS, G. (Orgs.). O Brasil na virada do século. Rio de Janeiro: Relume-Dumará, 1995.

O final da cadeia - Interpretações da violência no Rio. Disponível em: http://www.necvu. ifcs.ufrj.br/arquivos/O\%20final $\% 20 \mathrm{da} \% 20$ cadeia. pdf. Acesso em: 26.mar.2005. 
MONKEN, Mario Hugo. Estudo mostra vítimas indiretas da violência. Folha de S. Paulo, Caderno Cotidiano, p. C4, 28 de setembro de 2004.

MORIN. Edward. Risk of death. Revolution. Violence. Solidarity, Manila, vol. 5, n 1, p. 46-9. jan. 1970.

OLIVEN, R. G. Violência e cultura no Brasil. Petrópolis: Vozes, 1993.

PINHEIRO, Paulo Sérgio. Violência brasileira. São Paulo: Brasiliense, 1982.

ROLNIK, Raquel. Exclusão territorial e violência. São Paulo em Perspectiva, Fundação Seade, v.13, n.4. 1999. p.121-129.

SERASA. Guia Serasa de orientação ao cidadãoSaiba como reduzir o risco de ser vítima da violência. Disponível em: www.serasa.com.br/ serasalegal/15-jan-03_m1.htm. Acesso em: 26 de março de 2005.

SILVA, Alessandro. Criminosos dependem de facilidades. Folha de S. Paulo, Caderno Cotidiano, p. A3, 3 de fevereiro de 2002 a.

. Desinformação debilita combate ao crime. Folha de S. Paulo, Caderno Cotidiano, p. A3, 3 de fevereiro de $2002 \mathrm{~b}$.

SOUZA, Edinilsa Ramos de. Violência velada e revelada: Estudo epidemiológico da mortalidade por causas externas em Duque de Caxias. Rio de Janeiro, 1991. Dissertação (Mestrado) - ENSP/Fiocruz.

SUWWAN, Leila. Brasil é o $3^{\circ} \mathrm{em}$ morte de jovens, diz Unesco. Folha de S. Paulo, Caderno Cotidiano, p. C4, 4 de maio de 2002a.

SUWWAN, Leila. Entre 60 países, Brasil fica em terceiro em assassinato de jovens. Folha de $S$. Paulo, Caderno Cotidiano, p. C4, de 4 de maio de $2002 \mathrm{~b}$.
TAVARES DOS SANTOS, J.V.; DIDONET, B.; SIMON, C. A palavra e o gesto emparedados: a violência na escola. In: SECRETARIA MUNICIPAL DE EDUCAÇÃO DE PORTO ALEGRE (Org.). Violência não está com nada. Porto Alegre: Secretaria Municipal de Educação, 1998.

TEIXEIRA, Maria Cecília Sanches; PORTO, Maria do Rosário Silveira. Violência, insegurança e imaginário do medo. Cad. Cedes, dez. 1998, vol.19, n. 47, p. 51-66.

THORPE, William. Unesco Couiler, p. 40. ago.-set. 1970.

VALVERDE, Danielle Novaes de Siqueira. Controle da violência. Disponível em: http://www.abep.sp. gov.br/DOWNLOAD/Controle $\% 20 \mathrm{da} \% 20$ violencia $\% 20$ crim.doc. Acesso em: 21 de fevereiro de 2005.

VELHO, Gilberto. Violência, reciprocidade e desigualdade: Uma perspectiva antropológica. In: VELHO, Gilberto; ALVITO, Marcos (Orgs.). Cidadania $e$ violência. Rio de Janeiro: Editora UFRJ/Editora FGV, 1996.

VELHO, Gilberto. O desafio da violência. ComCiência, Revista Eletrônica de Jornalismo Científico, n. 26, outubro de 2001. Disponível em: http://www. comciencia.br/reportagens/framereport.htm. Acesso em: 17/1/2005.

ZALUAR, Alba; LEAL, Maria Cristina. Violência extra e intramuros. Rev. Bras. Ciências Sociais, fev. 2001, vol.16, n. 45, p.145-164.

ZALUAR, Alba e outros. Violência, crime organizado e poder: a tragédia brasileira e seus desafios. In: VELLOSO, J.P.R. (Ed.) Governabilidade, sistema político e violência urbana. Rio de Janeiro: José Olympio, 1994. 
